Portland State University

PDXScholar

Civil and Environmental Engineering

Undergraduate Honors Theses

9-29-2017

\title{
Torrefaction Kinetics of Hemp Hurds, an Emerging Agricultural Byproduct, in a Small Retort
}

Tel Jensen

Portland State University

Follow this and additional works at: https://pdxscholar.library.pdx.edu/cengin_honorstheses

Part of the Energy Systems Commons, and the Sustainability Commons Let us know how access to this document benefits you.

\section{Recommended Citation}

Jensen, Tel, "Torrefaction Kinetics of Hemp Hurds, an Emerging Agricultural Byproduct, in a Small Retort" (2017). Civil and Environmental Engineering Undergraduate Honors Theses. 9.

https://doi.org/10.15760/honors.483

This Thesis is brought to you for free and open access. It has been accepted for inclusion in Civil and Environmental Engineering Undergraduate Honors Theses by an authorized administrator of PDXScholar. Please contact us if we can make this document more accessible: pdxscholar@pdx.edu. 
TORREFACTION KINETICS OF HEMP HURDS, AN EMERGING AGRICULTURAL BYPRODUCT, IN A SMALL RETORT

\section{BY}

\section{TEL JENSEN}

\section{A thesis submitted in partial fulfillment}

of the requirement for the degree of

\section{BACHELOR OF SCIENCE \\ IN \\ CIVIL AND ENVIRONMENTAL ENGINEERING}

Thesis Advisor:

Dr. G.R. Johnson

Portland State University

(C)2017 


\section{ACKNOWLEDGMENTS}

Dr. Johnson, obviously.

Emily and Julie, for graciously enduring the smoke.

Corina, for Matlab help and fizz and snacks and commiseration.

Henry, for the hurds.

Äkräs, for everything, but especially the turnips. 


\begin{abstract}
As knowledge concerning the consequences of unsustainable energy sources and agricultural practices grows, development of low-impact alternatives to both becomes more important. Sustainable sources of biomass offer solutions to both problems. This study characterized the reaction kinetics of torrefying an agricultural byproduct, the woody interior of hemp stems, or hurds. Torrefaction was carried out at $250^{\circ} \mathrm{C}$ in small and simple retorts made of galvanized steel pipe. A first-order model most closely approximated the reaction. A sensitivity analysis was performed and the data was adjusted to correct for three potential sources of error, and regressed to find the best fit in each case. When corrected for torrefaction time, initial moisture content, and final mass loss, the best fit regressions for mass loss with time yielded governing equations $L=0.5388 \times\left(1-e^{-0.003069(t+113)}\right), L=$ $0.4523 \times\left(1-e^{-0.003015 t}\right)$, and $L=0.4088 \times\left(1-e^{-0.008718 t}\right)$, respectively. Regression of uncorrected data gave the governing equation $L=0.5388 \times\left(1-e^{-0.004682 t}\right)$. Results of this study indicate that the conversion of hemp hurds via torrefaction follows first-order reaction kinetics and that reaction is most sensitive to the torrefaction time under fixed-bed, isothermal conditions.
\end{abstract}




\section{TABLE OF CONTENTS}

1.0 INTRODUCTION

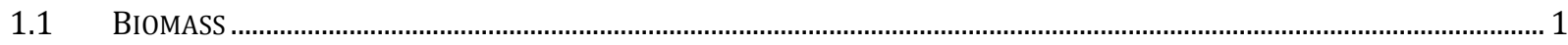

1.2 HEMP HURDS.

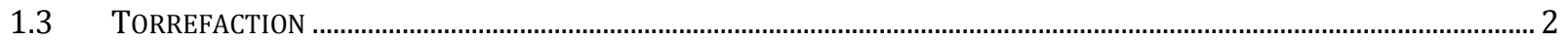

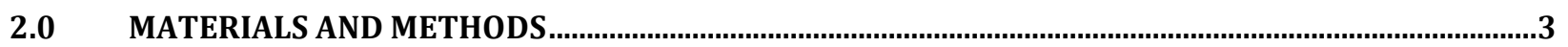

2.1 InSTRUMENTATION, APPARATUS, EXPERIMENTAL PROCEDURE................................................................................... 3

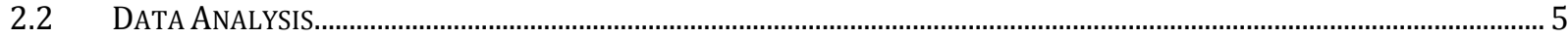

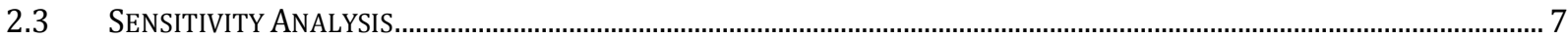

$3.0 \quad$ RESULTS AND DISCUSSION

4.0 CONCLUSIONS

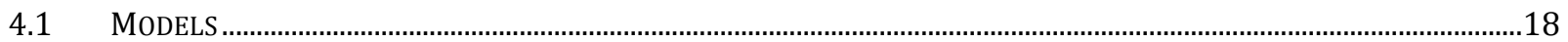

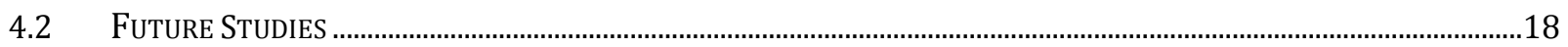

Exclude Oxygen.............................................................................................................................................................. 18

Measure temperature inside retorts............................................................................................................................18

Account for moisture content .......................................................................................................................................18

$4.3 \quad$ ADDITIONAL EXPERIMENTAL DATA AND ANALYSIS.....................................................................................................19

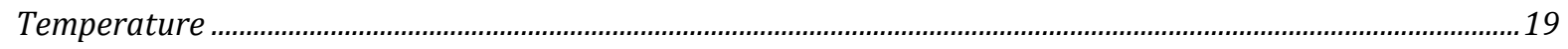

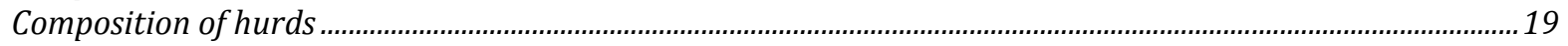

Composition of gaseous products................................................................................................................................. 19

Energy and economic evaluations .......................................................................................................................

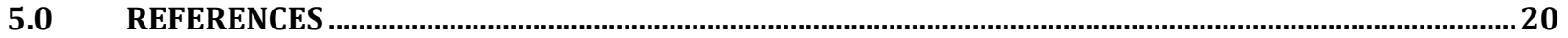




\section{LIST OF TABLES}

Table 1 Torrefaction model coeficients.............................................................................................................................17 


\section{LIST OF FIGURES}

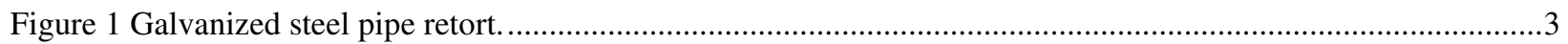

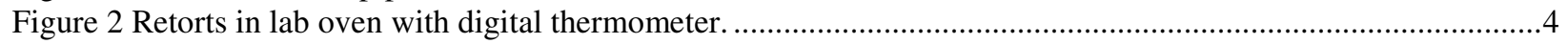

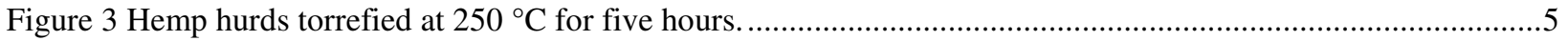

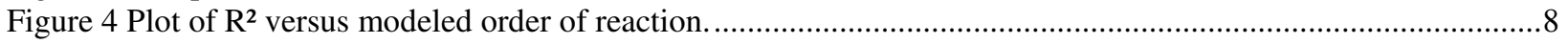

Figure 5 Plot of mass conversion versus torrefaction time at $250{ }^{\circ} \mathrm{C}$ with linear regression. Error bars are one

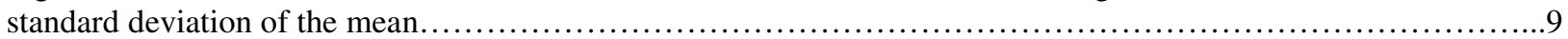

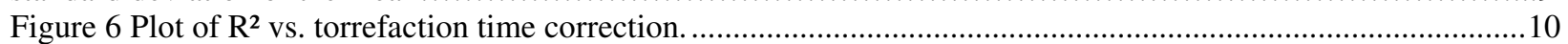

Figure 7 Representative measured temperature profiles for torrefaction of hemp hurds.......................................11

Figure $8 \mathrm{Model}$ corrected for torrefaction time plotted with measured data. Error bars are one standard deviation in

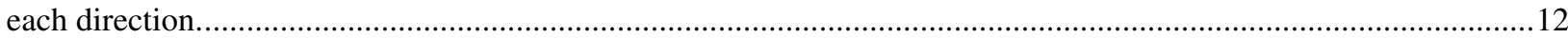

Figure 9 Plot of $\mathrm{R}^{2}$ vs. correction for initial moisture content of hurds. ..........................................................13 Figure 10 Model corrected for initial moisture content with measured data. Error bars extend one standard deviation

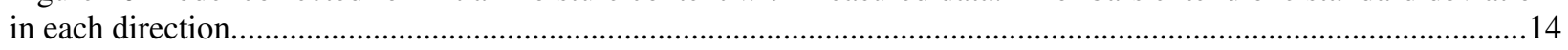

Figure 11 Plot of $\mathrm{R}^{2} \mathrm{v}$ f final mass loss correction. ................................................................................. 15

Figure 12 Model corrected for final mass loss and measured data. Error bars extend one standard deviation each

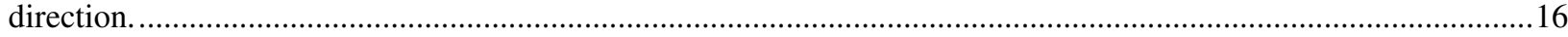




\subsection{INTRODUCTION}

\subsection{Biomass}

As the negative impacts of fossil fuel use, from extraction (Butt et al. 2013; Bouman et al. 2015; Griffith et al. 2012) through processing (Mangmeechai et al. 2014), transportation (Obida et al. 2017), and finally consumption (Pecl et al. 2017), are better understood, the need for tools and alternatives to mitigate those impacts become clearer. A variety of methods using biomass as a raw material may accomplish both goals as they may sequester carbon (Abdel-Fattah et al. 2015) and/or provide alternative fuels (Yue et al. 2014), among other benefits.

Some forms and uses of biomass, however, have significant drawbacks. For example, agricultural practices used to grow rapeseed and corn (maize) for biodiesel and bioethanol production, respectively, increase $\mathrm{N}_{2} \mathrm{O}$ emissions. The additions of $\mathrm{N}_{2} \mathrm{O}$ may negate any climate benefits of a reduction in carbon emissions that result from replacing fossil fuel (Crutzen et al. 2016). Additionally, augmenting forest soils with biochar can lead to faster decomposition of native organic matter and higher rates of soil $\mathrm{CO}_{2}$ respiration (Mitchell et al. 2015), again reducing climate benefits.

\subsection{Hemp hurds}

Many useful products are derived from hemp. The fibers are used for paper, textiles, insulation, and biocomposites. Hemp seeds and seed oil are used for human food and animal feed. Hemp seed oil is also used in oil-based paint, cosmetics, and as a raw material for plastics (Carus et al. 2013). Epidermal appendages, called trichomes, contain several terpenophenolic compounds, including cannabidiol, which has therapeutic potential for a number of disorders in addition to acting as an antioxidant (Cherney et al. 2016). Finally, the inner woody core of the hemp plant, called hurds or shivs, is used as animal bedding and, combined with lime, as a crack-proof construction material (Carus et al. 2013). This last portion of the hemp plant, the hurds, is the lowest value material but produced in the largest quantities, with 1.7 times the mass of hurds produced as hemp fiber (Ibid.). 
As the market for hemp products continues to grow, research has shown hemp production can provide significant environmental benefits as compared to typical large-scale agricultural crops. For example, in Europe, hemp (Cannabis sativa) is cultivated without the use of synthetic chemical fertilizers or pesticides, even on farms that are not organic (Carus et al. 2013). A life cycle assessment found that hemp cultivation sequesters a net of 26.01 tons $\mathrm{CO}_{2}$ equivalent/ha (Zampori et al. 2013). In 2016, the Oregon legislature passed a law allowing a limited amount of industrial hemp cultivation in the state. Depending on the outcome of these initial trials and the future political environment in Oregon and the USA, hemp hurds could become an abundant local agricultural byproduct and source of biomass.

\subsection{Torrefaction}

Torrefaction is pyrolysis of biomass that takes place between 225 and $300{ }^{\circ} \mathrm{C}$. Woody and herbaceous biomass is largely made up of cellulose, hemicellulose, and lignin (Bergman 2005). Hemicelluloses are the most reactive compounds in woody biomass, and decompose at temperatures between 225 and $325^{\circ} \mathrm{C}$. Lignin decomposes gradually at temperatures between 250 and $500{ }^{\circ} \mathrm{C}$. The temperature range at which cellulose decomposes, 305-375 ${ }^{\circ} \mathrm{C}$, falls outside that considered for torrefaction (Prins 2006).

Biomass is often torrefied to make it more suitable for intended use (e.g., energy production). Torrefaction increases biomass's energy density by removing less-energy dense volatile constituents. It is also made easier to grind, pelletize, and transport (Bergman 2005).

This honors thesis project aims to characterize and optimize the torrefaction of various raw biomass materials using fixed-bed torrefaction and low oxygen content sample retorts. Initial experiments were conducted using hazelnut shells and hemp hurds. Further experiments and characterization of the torrefaction of hemp hurds was done to determine the efficiency of fixed-bed torrefaction for the production of hemp biochars. Data analysis included the determination of the best fit model for the order of reaction and kinetic coefficients of that reaction. A sensitivity analysis to determine the impact of various experimental conditions on the optimization of the torrefaction process was also conducted. 


\subsection{MATERIALS AND METHODS}

\subsection{Instrumentation, Apparatus, Experimental Procedure}

Eight (8) trials using hemp hurds (Item number F-H3, Hemp Traders, Paramount, CA) were packed into four (4) small retorts made of threaded sections of galvanized pipe $(120 \mathrm{~mm}$ long, $27 \mathrm{~mm}$ internal diameter) and capped tightly using a pipe wrench (Figure 1).

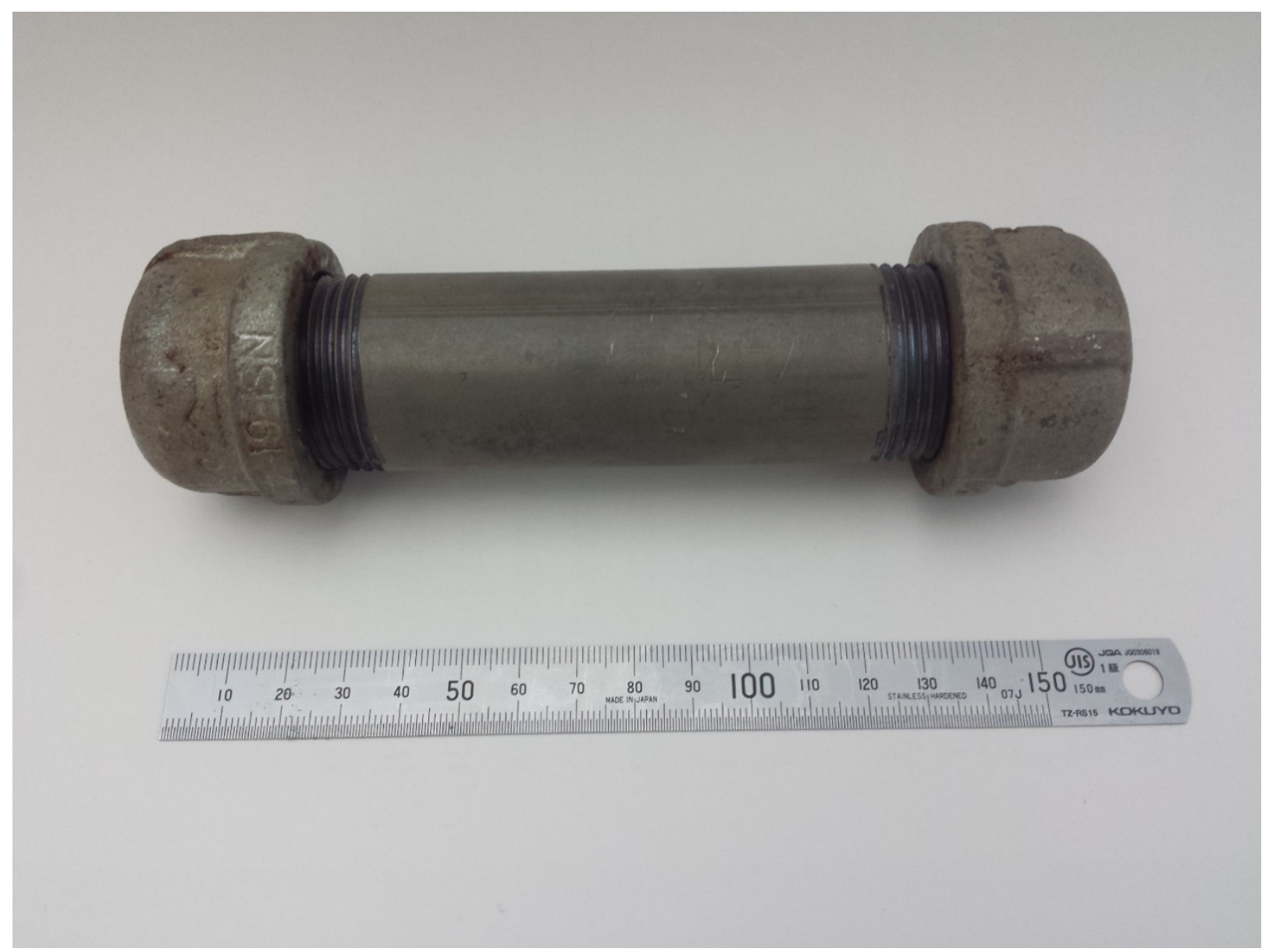

Figure 1. Galvanized steel pipe retort.

The mass of hurds in each retort was determined by weighing retorts before and after packing (Mettler PJ3600 DeltaRange). Retorts were placed side-by-side on the same rack in a small laboratory oven (Blue M Electric Company Stabil-Therm B-1206Q-A) (Figure 2). Temperature was recorded at one-minute intervals using a digital thermometer (6802 II) with a thermocouple probe inserted into the top of the oven. The oven temperature was set to reference number 25 and power set to high for all trials. At the end of each trial's time, the 
oven was turned off and the door opened to allow consistent cooling while the retorts remained in the oven. After the retorts had cooled to room temperature, each was weighed. The torrefied hurds were emptied into aluminum weigh boats (Figure 3) and weighed, and the empty retorts were weighed again.

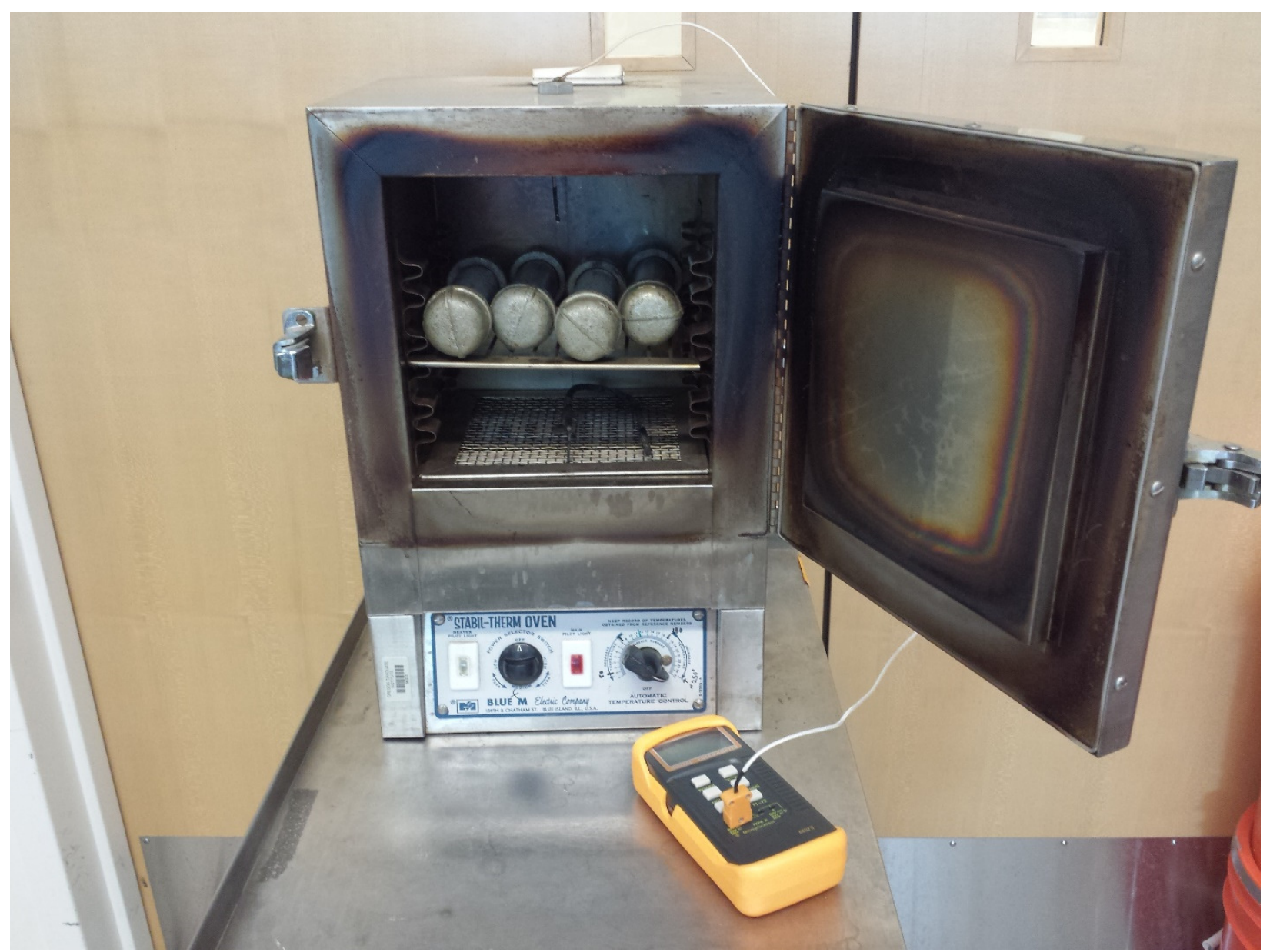

Figure 2. Retorts in lab oven with digital thermometer. 


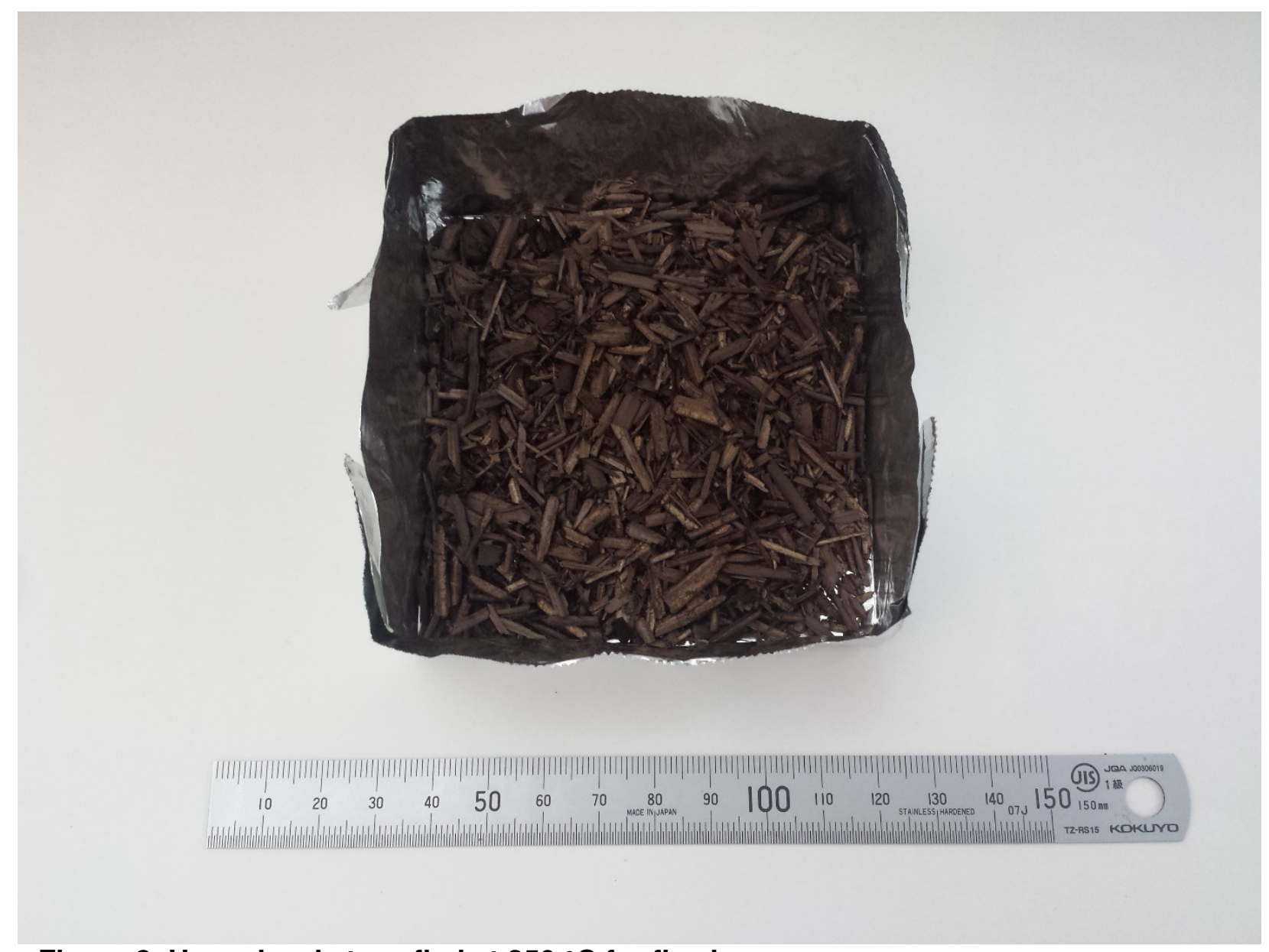

Figure 3. Hemp hurds torrefied at $250^{\circ} \mathrm{C}$ for five hours.

It should be noted that no attempt was made to exclude oxygen from the retorts. They were packed under ambient atmospheric conditions, so some oxygen was present. Torrefaction is defined as thermal degradation in the absence of oxygen. However, the mass of oxygen in the retorts was small initially, and it would have decreased as the gas in the retort heated and was forced out through the threads. It is unlikely that more than a negligible amount of air was able to flow back into the heated retorts.

\subsection{Data Analysis}

Calculation of kinetic coefficients and constants roughly followed Chen and Kuo (2011). Specifically, the rate of reaction is given by the following equation:

$$
\frac{d X}{d t}=k(1-X)^{n}
$$


where $n$ is the order of the reaction, $k$ is the reaction rate constant, $t$ is torrefaction time, and $X$ is the fractional conversion of the sample, defined as

$$
X=\frac{L}{L_{48}}
$$

$L$ is the fractional mass loss of the sample, defined as

$$
L=\frac{M_{i}-M}{M_{i}}
$$

where $M_{i}$ is the initial mass of the sample and $M$ is the mass of the sample after torrefaction. $L 48$ is the fractional mass loss after isothermal torrefaction for 48 hours, defined as

$$
L_{48}=\frac{M_{i}-M_{48}}{M_{i}}
$$

where $M_{48}$ is the mass of the sample after 48 hours of isothermal torrefaction.

If $n$, the order of the reaction, is 1, integration of Equation (1) yields

$$
\ln \frac{1}{1-X}=k t
$$

and a plot of $\ln \frac{1}{1-x}$ against torrefaction time will give a straight line with slope equal to the rate constant, $k$. Solving this equation for conversion, $X$, gives

$$
X=1-e^{-k t}
$$

and solving for mass loss, $L$

$$
L=L_{48} \times\left(1-e^{-k t}\right)
$$

If $n$ is not equal to 1, integrating Equation (1) yields

$$
(1-X)^{1-n}-1=k(n-1) t
$$


and a plot of $(1-X)^{1-n}-1$ against torrefaction time will give a straight line with slope equal to $k(n-1)$.

\subsection{Sensitivity Analysis}

A sensitivity analysis was conducted to determine how sensitive the experimental results are to three experimental variables: the isothermal torrefaction time, moisture content of the hurds, and the optimal mass conversion. These experimental variables were chosen based on observations made during data collection. For example, it was not feasible to measure temperature inside the retorts, so the air temperature in the oven directly above the retorts was measured during torrefaction. As such, the true isothermal torrefaction time may vary across replicate experiments. Furthermore, complete mass conversion of the hemp hurds was assumed after 48 hours of torrefaction time, thereby allowing for only an estimation of the long-term maximum mass conversion. Measured data was adjusted to account for these experimental variables, data was then regressed, and the highest $R^{2}$ value was assumed to correspond with the most likely true value. Each adjustment (for each of the three experimental variables tested) was performed on the raw data separately. It may be of interest to note that an attempt was made to perform all three adjustments concurrently, but the analysis failed to converge on a best-fit solution. 


\subsection{RESULTS AND DISCUSSION}

The experimental data was regressed assuming reaction kinetics following Chen and Kuo (2011) and presented in Equation (1). The order of reaction integer value $n$ was varied from 1 through 10 and the intercept forced to zero (Figure 4). $R^{2}$ values for each value of $n$ were compared, and the $n$ with the highest $R^{2}$ representing the most likely (best fit) reaction order.

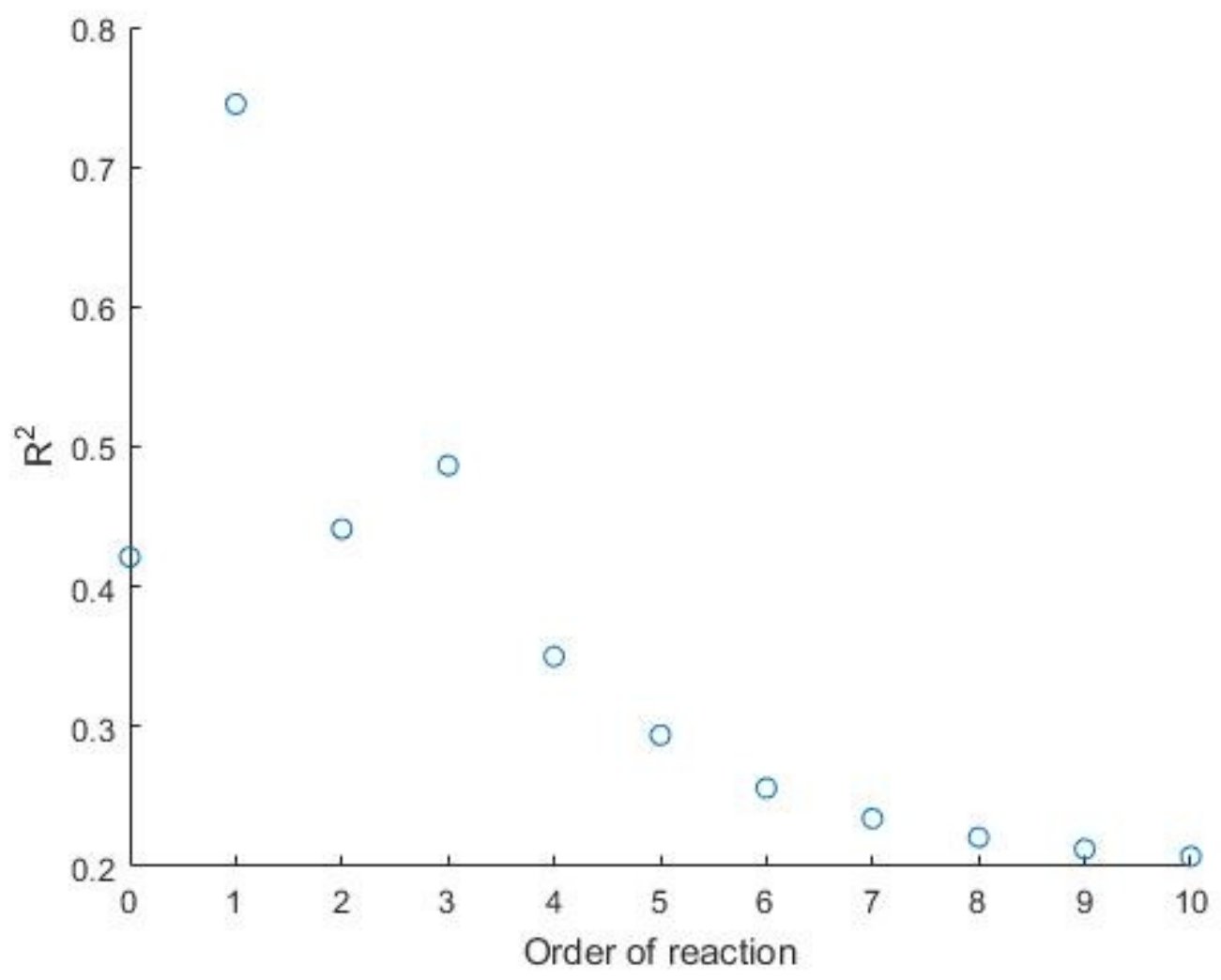

Figure 4. Plot of $\mathbf{R}^{2}$ versus modeled order of reaction.

When the data was regressed using integer values of $n$ from 0 through 10 , the regression with $n=1$ gave highest $R^{2}, 0.7449$ (as shown in Figure 4). All subsequent results assume a first-order reaction to describe the thermal conversion of raw hemp hurds to hemp biochar under torrefaction.

To further characterize reaction kinetics of the hemp hurds' thermal conversion, integration of the best-fit governing equation (see Equation 5) and regression of the transformed raw 
data gave a reaction rate constant of $4.682 \times 10^{-3}$ day-1 $^{-1}$ (Figure 5) with the following governing first-order equation:

$$
L=0.5388 \times\left(1-e^{-0.004682 t}\right)
$$

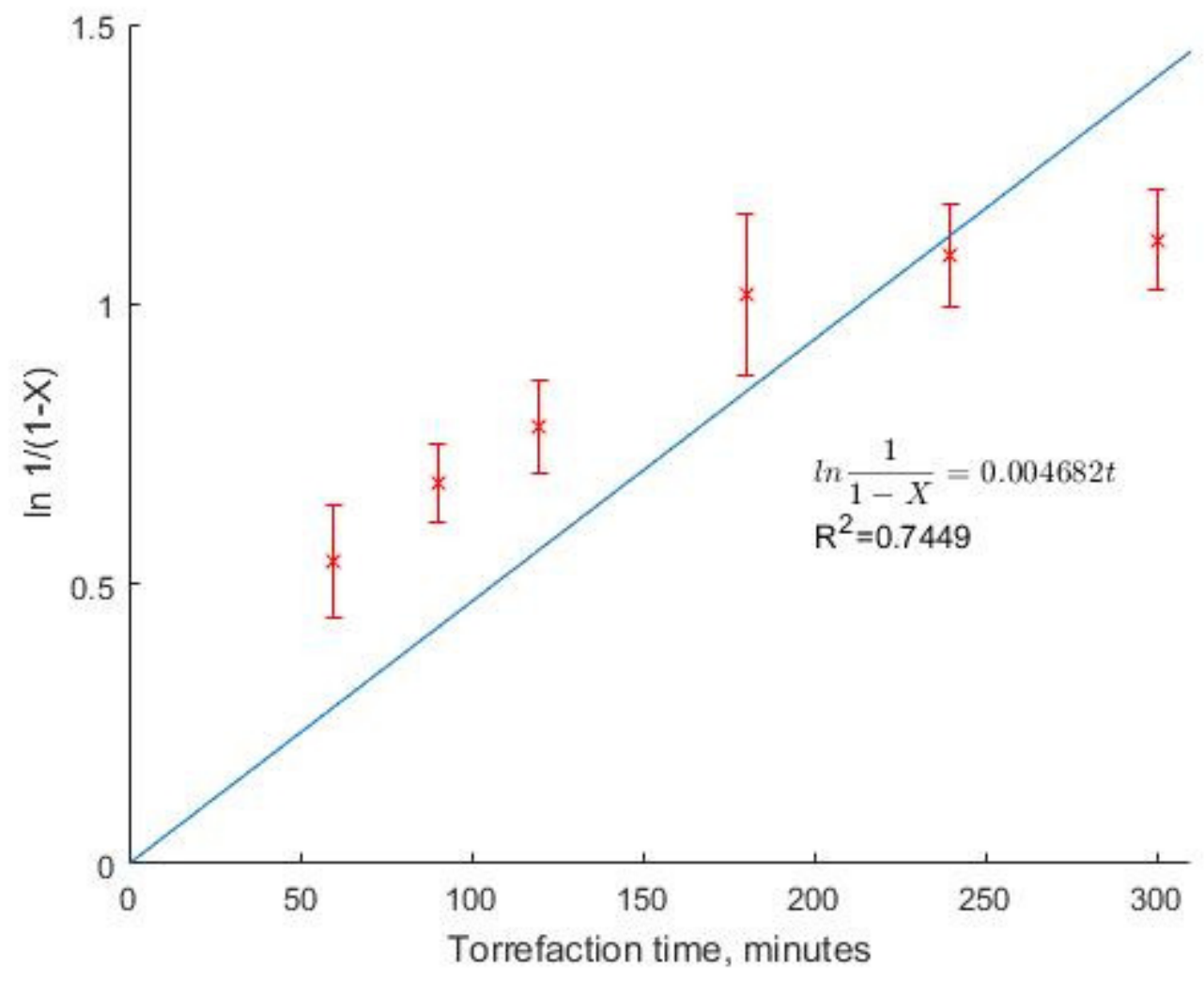

Figure 5. Plot of mass conversion versus torrefaction time at $250^{\circ} \mathrm{C}$ with linear regression. Error bars are one standard deviation of mean.

In an attempt to determine the effect/sensitivity of torrefaction time on the best-fit first order equation determined in this analysis, the torrefaction time, $t$, for each trial was shifted by between -180 and 180 minutes in 1-minute increments (Figure 6). 


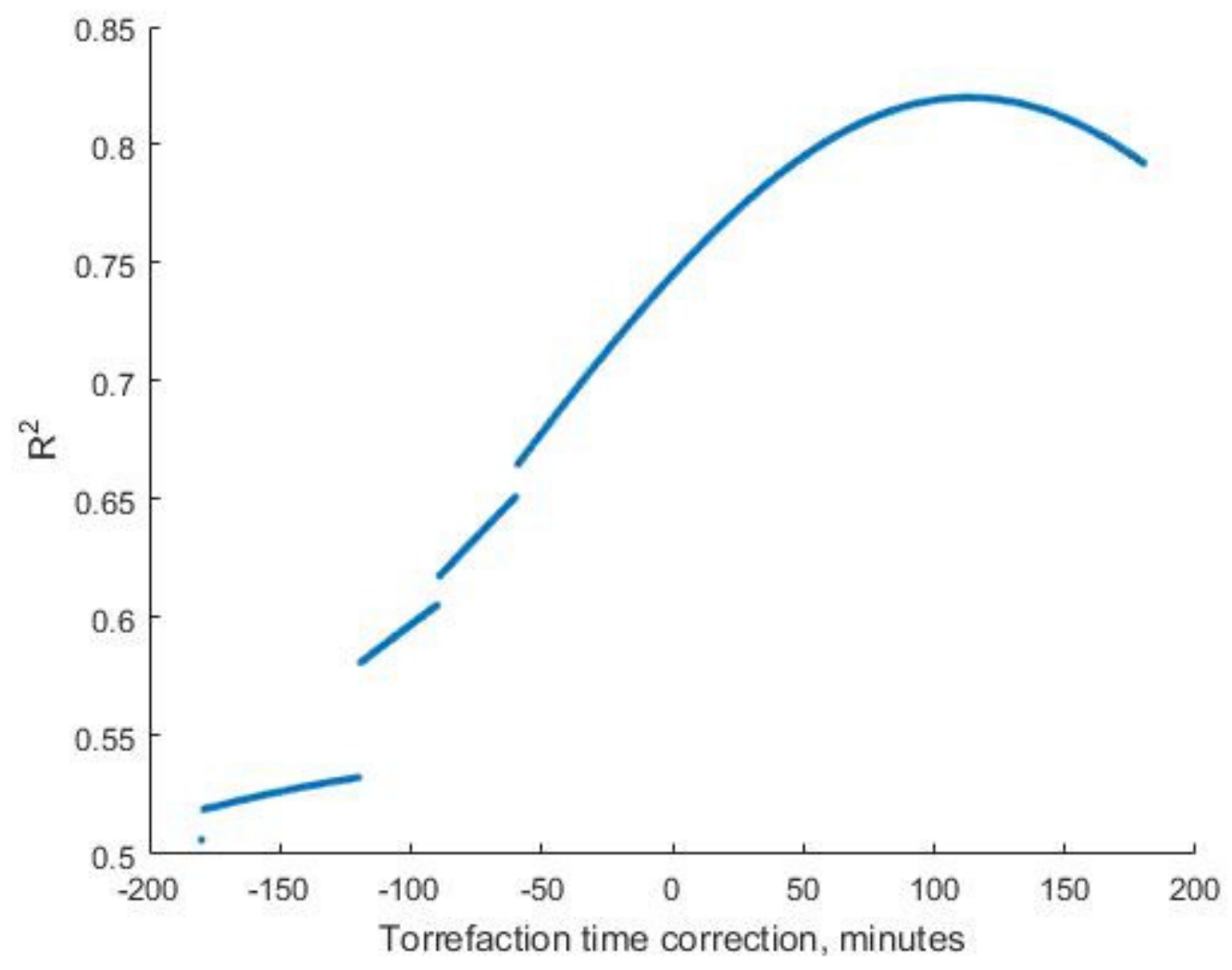

Figure 6. Plot of $\mathbf{R}^{2} v s$. torrefaction time correction.

The highest $R^{2}$ for adjusted torrefaction time was 0.8200 with a time shift of 113 minutes (Figure 6). Given that the temperature of the hurds lagged behind the measured air temperature in the oven, and that the air temperature of the oven did not reach torrefaction temperature of $200{ }^{\circ} \mathrm{C}$ for approximately 20 minutes after the beginning of heating and for approximately 60 minutes for $250{ }^{\circ} \mathrm{C}$ (see Figure 7), this suggests that the temperature of the hurds remained above torrefaction temperature well after the end of heating. Adjusting Equation 9 for torrefaction time (Figure 8) gives the governing equation:

$$
L=0.5388 \times\left(1-e^{-0.003069(t+113)}\right)
$$




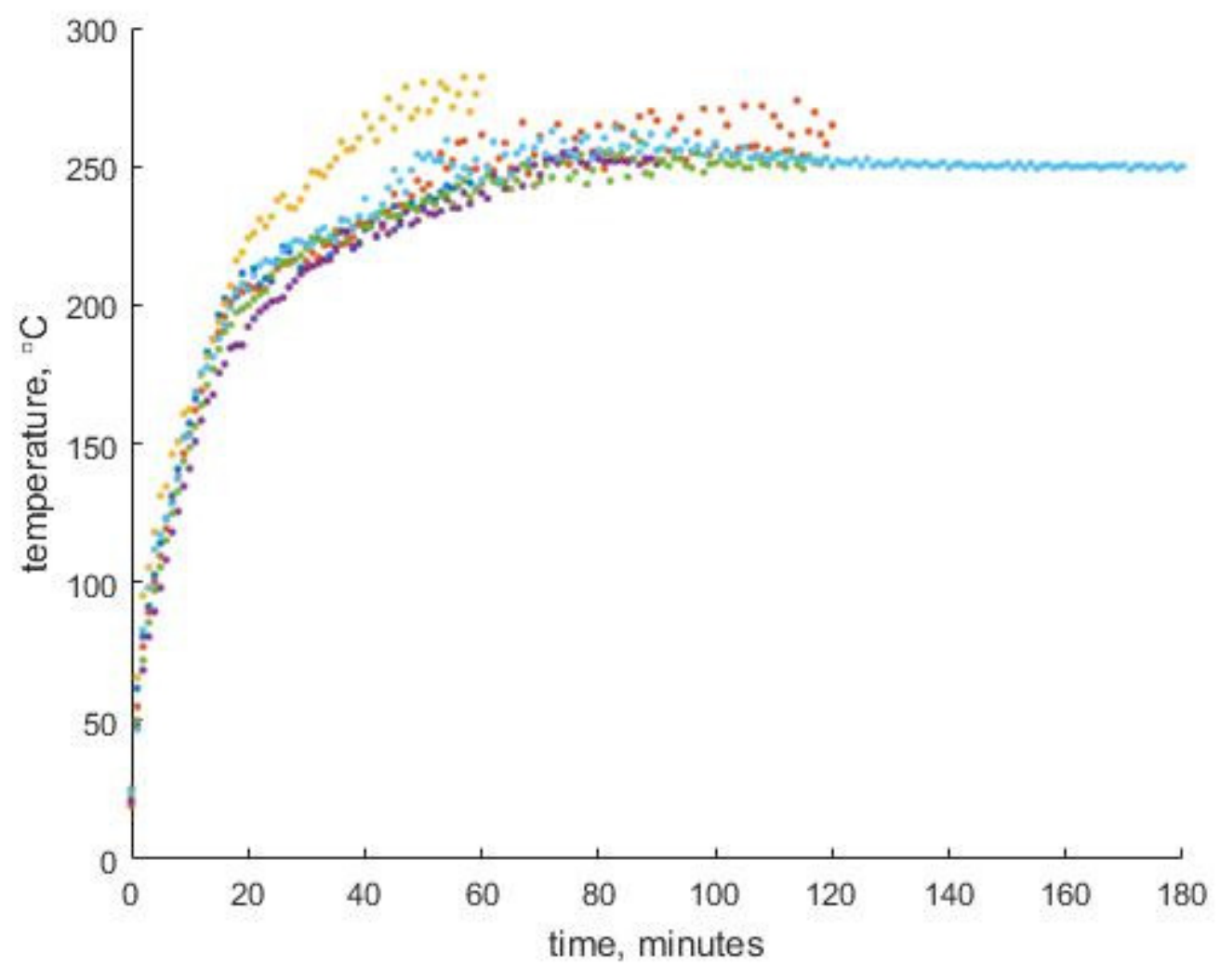

Figure 7. Representative measured temperature profiles for torrefaction of hemp hurds. 


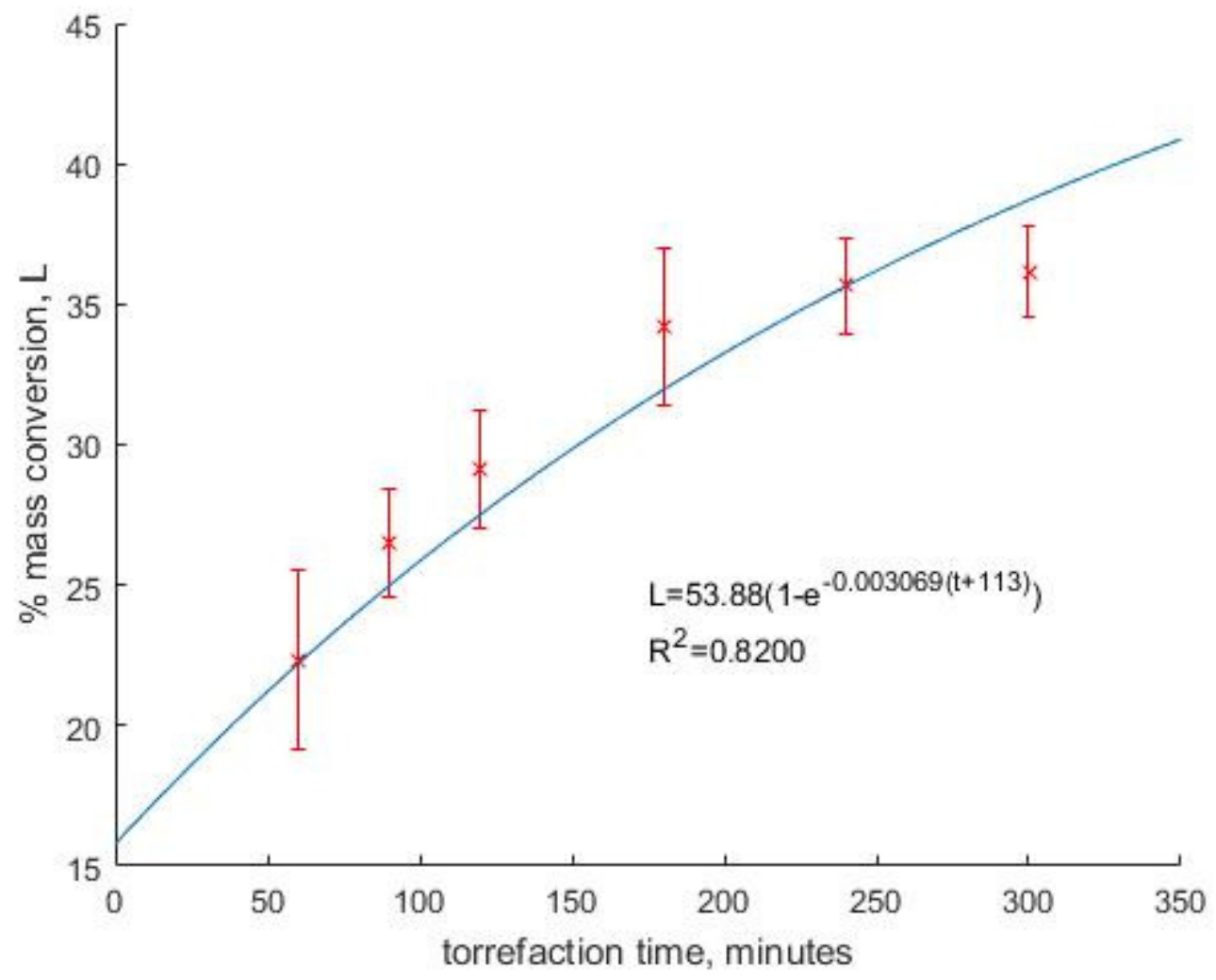

Figure 8. Model corrected for torrefaction time plotted with measured data. Error bars are one standard deviation in each direction.

To account for initial moisture content, the initial mass, $M_{i}$ (see Eq. 3), was reduced by between 0 and $20 \%$ in $0.1 \%$-increments (Figure 9). It is assumed that all initial moisture was driven off during torrefaction. 


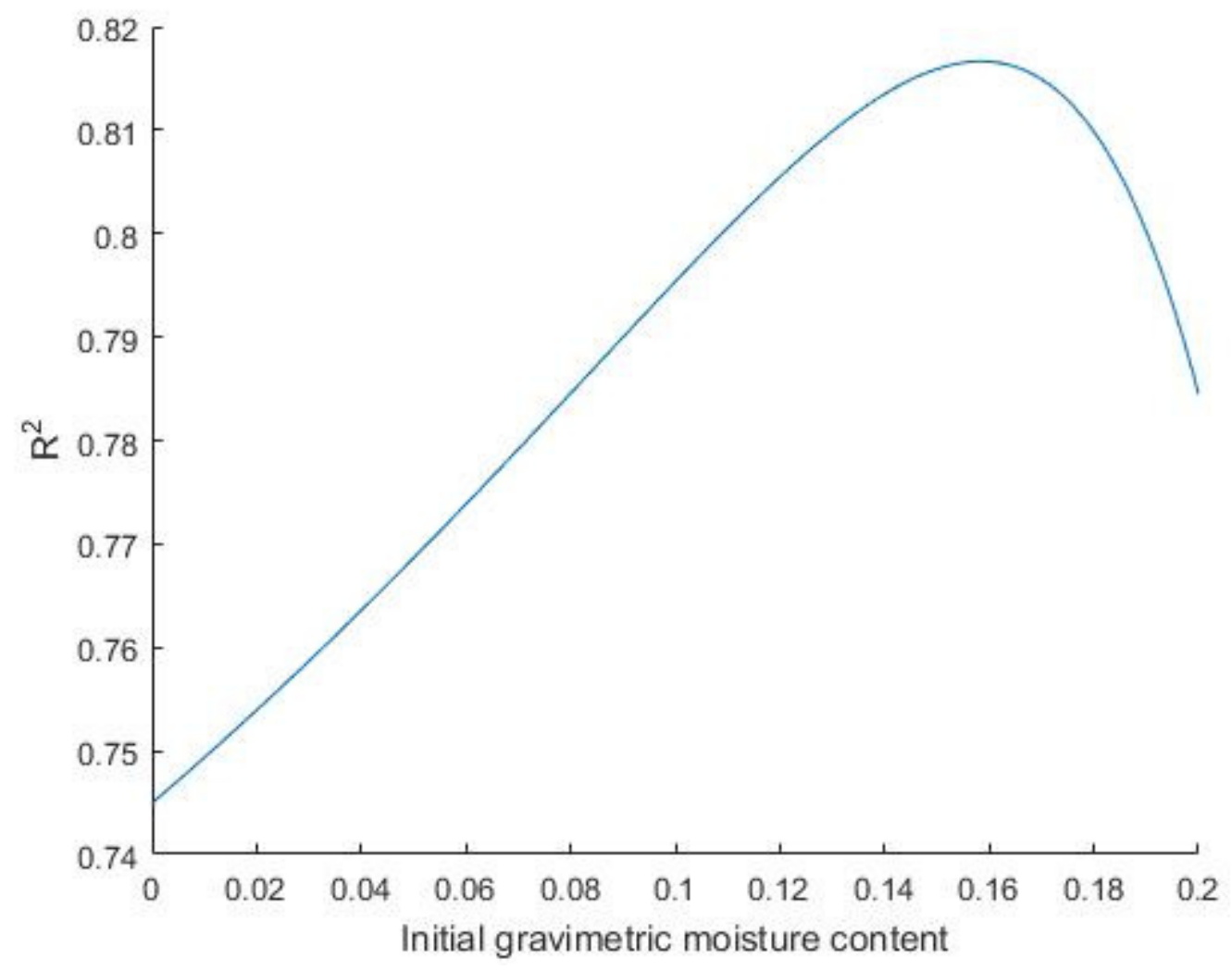

Figure 9. Plot of $R^{2}$ vs. correction for initial moisture content of hurds.

The highest $R^{2}$ after adjusting for moisture content was 0.8166 at $15.9 \%$ moisture (Figure 10). This magnitude of moisture content falls in the range of equilibrium moisture contents (EMC) that Nilsson et al. (2005) found for hemp stalks, and agrees with the values of EMC that Kymäläinen and Pasila (2000) found for coarse green hemp hurds. Adjusted for initial moisture content, the governing equation becomes:

$$
L=0.4523 \times\left(1-e^{-0.003015 t}\right)
$$




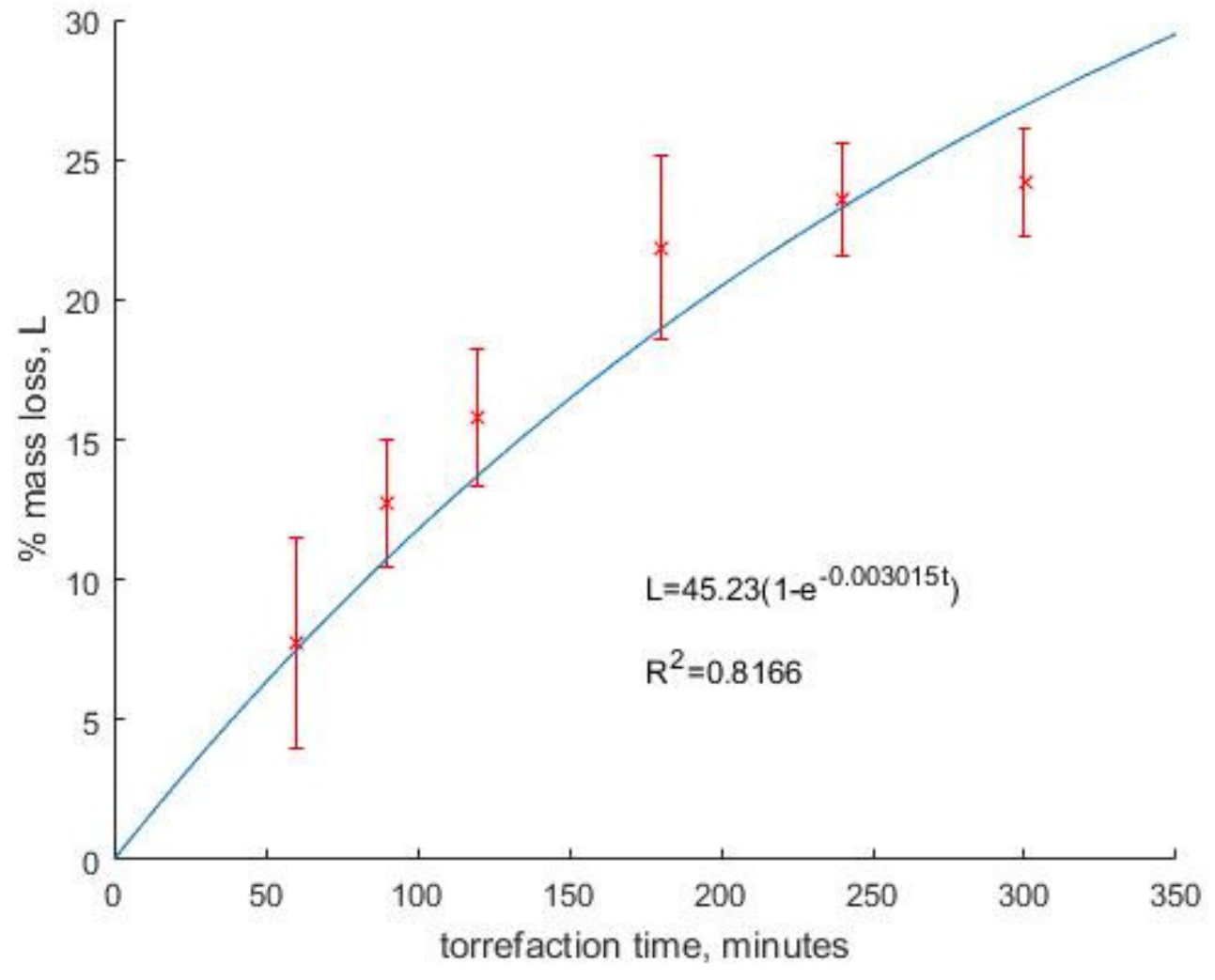

Figure 10. Model corrected for initial moisture content with measured data. Error bars extend one standard deviation in each direction.

To determine the sensitivity of the best-fit model to the assumed long-term final mass conversion time of 48 hours, the 48 -hour torrefaction mass loss term, $L 48$, was adjusted by adding between -14 and $46 \%$ in increments of $0.25 \%$ (Figure 11 ). 


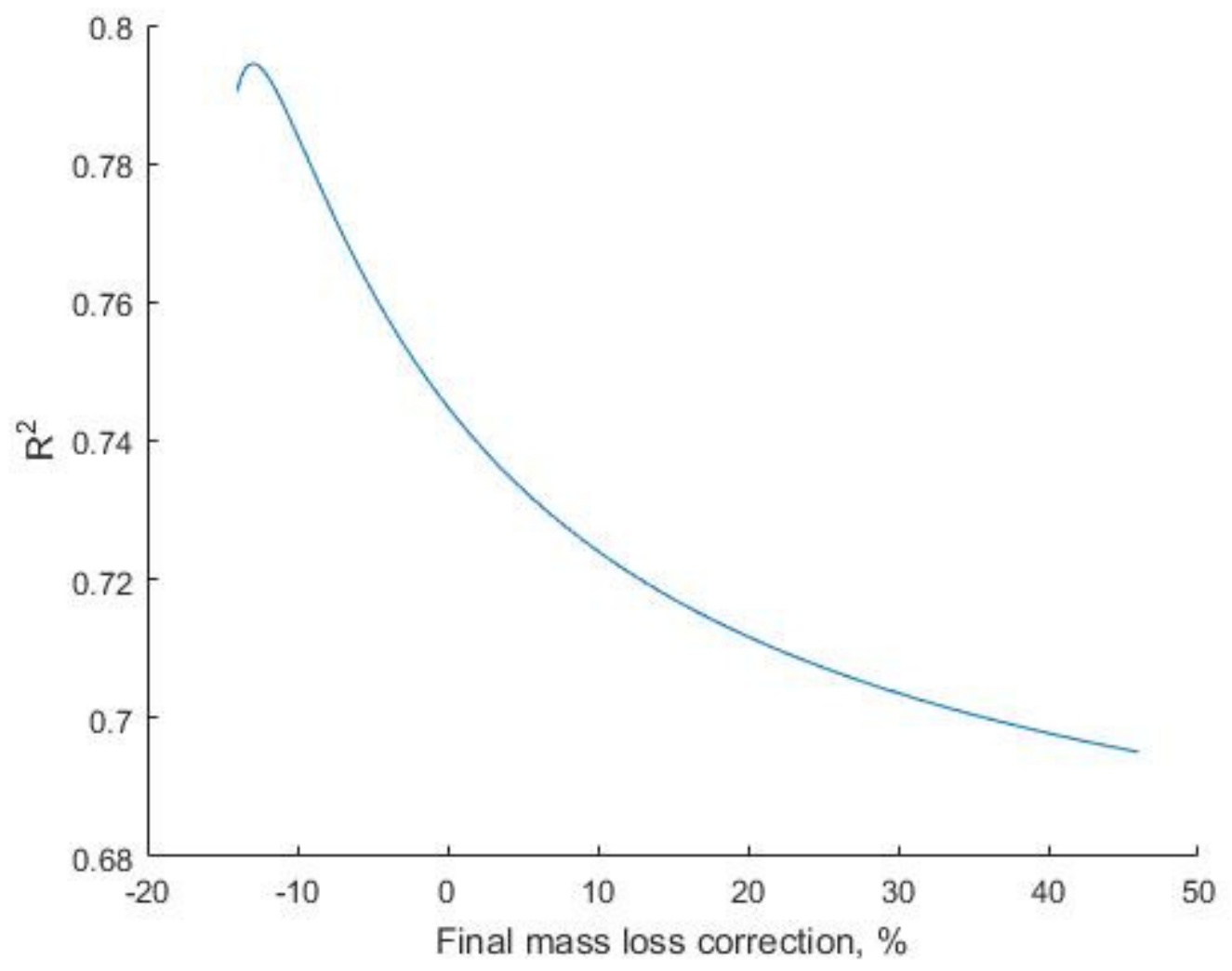

Figure 11. Plot of $\mathbf{R}^{2}$ vs. final mass loss correction.

The highest $R^{2}$ for adjusted final mass loss was 0.7944 at an adjustment to the final mass loss of $-13 \%$ (Figure 12). This result suggests that the long-term final mass loss is less than the mass loss after 48 hours, which is physically invalid. This result is likely an artifact of the sensitivity analysis being conducted in discrete steps. Specifically, as mentioned previously, the sensitivity analysis conducted herein was performed for the three experimental variables separately. This means that the best-fit solutions obtained during this sensitivity analysis (as summarized in Table 1) provide lumped-term corrections for the various experimental parameters tested herein (i.e., torrefaction time, initial moisture content, and optimal mass conversion torrefaction time).

Further sensitivity analyses for these three variables with data adjustments done in sequence could benefit final analyses of these experimental results. For example, the adjusted data resulting from sensitivity analysis performed on the torrefaction time could 
be tested for sensitivity to initial moisture content and so forth. Additionally, it could be that over 48 hours of torrefaction in the fixed-bed torrefaction system, air was able to circulate into the retorts and redox reactions took place. Further analysis of the hemp biochar for chemical composition could also benefit final analyses of these results. Modifying the governing equation for corrected final mass loss gives:

$$
L=0.4088 \times\left(1-e^{-0.008718 t}\right)
$$

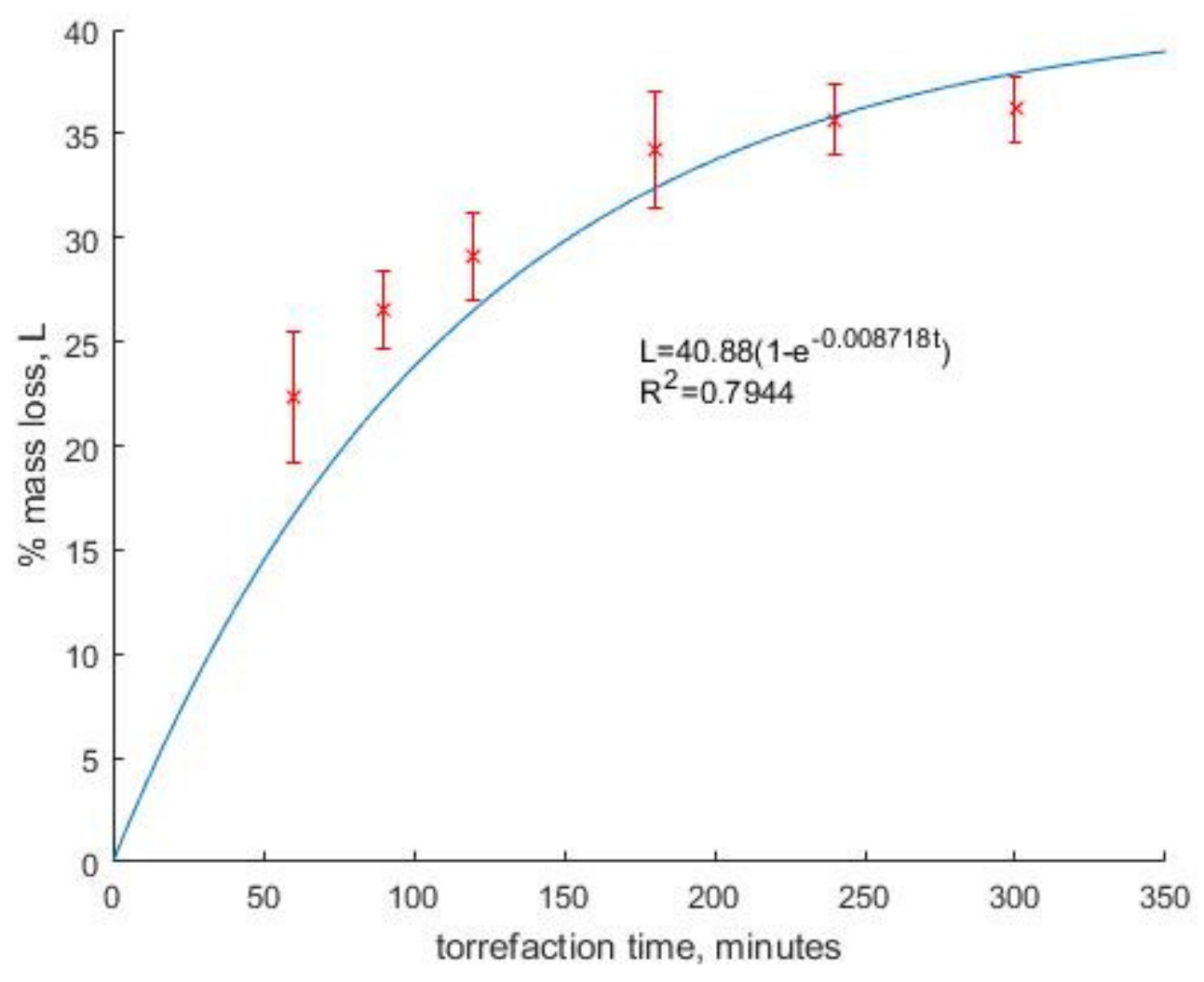

Figure 12. Model corrected for final mass loss and measured data. Error bars extend one standard deviation each direction. 
Table 1. First-order reaction kinetics model coefficients.

\begin{tabular}{|c|c|c|c|}
\hline Model & $L_{48}(\%)$ & $k\left(\mathrm{~min}^{-1}\right)$ & $R^{2}$ \\
\hline Raw data & 53.88 & 0.004682 & 0.7449 \\
\hline Time corrected & 53.88 & 0.003069 & 0.8200 \\
\hline Moisture content & 45.23 & 0.003015 & 0.8166 \\
\hline Final mass loss & 40.88 & 0.008718 & 0.7944 \\
\hline
\end{tabular}




\subsection{CONCLUSIONS}

\subsection{Models}

Four governing equations were developed to model the reaction kinetics of the torrefaction of hemp under isothermal conditions in a fixed-bed torrefaction system at $250{ }^{\circ} \mathrm{C}$ in small retorts. Results of the sensitivity analysis on three experimental variables (i.e., torrefaction time, initial moisture content, and optimal mass conversion) showed that the model including an adjustment for the isothermal torrefaction time had the highest $R^{2}$ value.

\subsection{Future Studies}

More advanced analytical instrumentation could be used to reduce error, but the expense of such instrumentation is difficult to justify. Instead, careful experimental design could accomplish similar reduction of error while adding much less to the cost of the study. To eliminate some of the sources of error identified, the following changes should be made:

\section{Exclude Oxygen}

Remove oxygen from the retorts by purging with nitrogen before heating begins. Maintain a flow of nitrogen into the retorts sufficient to exclude air from entering for the duration of torrefaction and until the retorts have cooled below temperatures that support thermal degradation.

\section{Measure temperature inside retorts}

The correlation between air temperature in the oven and the temperature inside the retorts is not known. Rather than trying to determine this correlation, it would likely be more reliable to measure the retort temperature directly.

\section{$\underline{\text { Account for moisture content }}$}

As a hygroscopic material, the moisture content of hemp hurds fluctuates with relative humidity. Keeping the hurds sealed in a temperature-controlled and air-tight container would reduce the variation in moisture content between trials to negligible levels. A simple oven drying test for moisture content would then be sufficient to account for this variable. Alternately, oven drying each sample prior to weighing and torrefaction would also remove moisture content from the calculation. 


\subsection{Additional Experimental Data and Analysis}

\section{$\underline{\text { Temperature }}$}

Repeating these experiments under a range of temperatures would allow development of relations between kinetic coefficients and temperature, as in Chen and Kuo (2011).

\section{Composition of hurds}

Determining the composition of raw hurds, prior to torrefaction, would allow comparisons and correlations of kinetic models with other biomasses of known composition as well as isolated constituents, such as in Chen and Kuo (2011). Analyzing the composition of the hurds after torrefaction would allow a better understanding of the chemical processes involved and development of models with a theoretical basis rather than purely empirical data. Additionally, characterization of the biochars produced after torrefaction as either an alternative fuel or possibly as a soil additive would be helpful.

\section{Composition of gaseous products}

Gases evolved during torrefaction represent a substantial fraction of the chemical energy contained in biomass. Collecting these gases for use would be important for maximizing the economic and environmental utility of processing biomass. Collecting and analyzing torrefaction gases would complicate the study, but would yield useful information.

\section{Energy and economic evaluations}

For torrefaction to be a useful treatment for hemp hurds, it would need to be both economically and environmentally productive. If the energy required to accomplish the treatment is greater than the increase in energy density it affects, for instance, it would be difficult to justify for biomass energy uses (while the potential as a soil additive may be justified). Likewise, if the economic value of the products does not justify the expense of required energy and apparatus, the process is unlikely to be of practical use. 


\subsection{REFERENCES}

Abdel-Fattah, T. M., Mahmoud, M. E., Ahmed, S. B., Huff, M. D., Lee, J. W., \& Kumar, S. (2015). Biochar from woody biomass for removing metal contaminants and carbon sequestration. Journal of Industrial and Engineering Chemistry, 22, 103-109.

Bergman, P. C., \& Kiel, J. H. (2005). Torrefaction for biomass upgrading. In Proc. 14th European Biomass Conference, Paris, France (Vol. 2005, pp. 17-21).

Bouman, E. A., Ramirez, A., \& Hertwich, E. G. (2015). Multiregional environmental comparison of fossil fuel power generation-assessment of the contribution of fugitive emissions from conventional and unconventional fossil resources. International Journal of Greenhouse Gas Control, 33, 1-9.

Butt, N., Beyer, H. L., Bennett, J. R., Biggs, D., Maggini, R., Mills, M., \& Possingham, H. P. (2013). Biodiversity risks from fossil fuel extraction. Science, 342(6157), 425-426.

Carus, M., Karst, S., Kauffmann, A., Hobson, J., \& Bertucelli, S. (2013). The European Hemp Industry: Cultivation, processing and applications for fibres, shivs and seeds. European Industrial Hemp Association (EIHA), Hürth (Germany).

Chen, W. H., \& Kuo, P. C. (2011). Isothermal torrefaction kinetics of hemicellulose, cellulose, lignin and xylan using thermogravimetric analysis. Energy, 36(11), 6451-6460.

Cherney, J. H., \& Small, E. (2016). Industrial hemp in North America: Production, politics and potential. Agronomy, 6(4), 58.

Crutzen, P. J., Mosier, A. R., Smith, K. A., \& Winiwarter, W. (2016). N20 release from agrobiofuel production negates global warming reduction by replacing fossil fuels. In Paul J. Crutzen: a pioneer on atmospheric chemistry and climate change in the Anthropocene (pp. 227-238). Springer International Publishing.

Griffith, M. B., Norton, S. B., Alexander, L. C., Pollard, A. I., \& LeDuc, S. D. (2012). The effects of mountaintop mines and valley fills on the physicochemical quality of stream ecosystems in the central Appalachians: a review. Science of the Total Environment, 417, 1-12.

Kymäläinen, H. R., \& Pasila, A. (2000). Equilibrium moisture content of flax/linseed and fibre hemp straw fractions. Agricultural and Food Science in Finland, 9, 259-268

Mangmeechai, A., Jaramillo, P., Griffin, W. M., \& Matthews, H. S. (2014). Life cycle consumptive water use for oil shale development and implications for water supply in the Colorado River Basin. The International Journal of Life Cycle Assessment, 19(3), 677-687.

Mitchell, P. J., Simpson, A. J., Soong, R., \& Simpson, M. J. (2015). Shifts in microbial community and water-extractable organic matter composition with biochar amendment in a temperate forest soil. Soil Biology and Biochemistry, 81, 244-254. 
Nilsson, D., Svennerstedt, B., \& Wretfors, C. (2005). Adsorption equilibrium moisture contents of flax straw, hemp stalks and reed canary grass. Biosystems engineering, 91(1), $35-43$.

Obida, C. B., Whyatt, J. D., Blackburn, A. G., \& Semple, K. T. (2017). Spatial Analysis along a Network: Human and Environmental Exposure to Pipeline Hydrocarbon Pollution in the Niger Delta.

Pecl, G. T., Araújo, M. B., Bell, J. D., Blanchard, J., Bonebrake, T. C., Chen, I. C., \& Falconi, L. (2017). Biodiversity redistribution under climate change: Impacts on ecosystems and human well-being. Science, 355(6332), eaai9214.

Prins, M. J., Ptasinski, K. J., \& Janssen, F. J. (2006). Torrefaction of wood: Part 1. Weight loss kinetics. Journal of analytical and applied pyrolysis, 77(1), 28-34.

Small, E. (2015). Evolution and classification of Cannabis sativa (marijuana, hemp) in relation to human utilization. The Botanical Review, 81(3), 189-294.

Yue, D., You, F., \& Snyder, S. W. (2014). Biomass-to-bioenergy and biofuel supply chain optimization: overview, key issues and challenges. Computers \& Chemical Engineering, 66, 36-56.

Zampori, L., Dotelli, G., \& Vernelli, V. (2013). Life cycle assessment of hemp cultivation and use of hemp-based thermal insulator materials in buildings. Environmental science \& technology, 47(13), 7413-7420. 